\title{
Challenges for Smart Electricity Meters due to Dynamic Power Quality Conditions of the Grid: a Review
}

\author{
Quijano Cetina, R., Andrew J. Roscoe \\ Department of Electronic and Electrical Engineering \\ University of Strathclyde, Glasgow, UK \\ renan.quijano-cetina@strath.ac.uk
}

\author{
P.S. Wright \\ National Physical Laboratory \\ Teddington, Middlesex, UK
}

\begin{abstract}
During the last few years, Smart Electricity Meters have been deployed in several countries all around the world, replacing the trustable Electromechanical meter and even other electronic meters. Since the early deployments, many concerns and complaints from customers which do not trust Smart Meters accuracy have appeared. As a result, researchers of different institutions have been testing electricity meters under distorted waveform conditions and proposing methods to calibrate such meters in a more representative real world operative conditions. Applicable accuracy standards and regulations indicate a maximum distortion factor of $3 \%$ of the sinusoidal waveform for voltage and current during the calibration, which is not representative of many modern dynamic power quality scenarios. New tests and recommendations have been issued by regulatory bodies, but they are still not mandatory for meters to be certified. With many changes upcoming in the near future for the electrical Smart Grid like the inclusion of renewables, increasing non-linear loads, electric charging vehicles and other emerging technologies, the power quality conditions of the grid is expected to be significantly affected. In this paper, a review of the current and upcoming challenges for the smart meters is presented.
\end{abstract}

Keywords-Accuracy; Smart Meter; Power Quality.

\section{INTRODUCTION}

The transition from a traditional electrical grid to the smart grid involves significative changes that imply new challenges to electricity meters [1]. In this dynamic scenario where energy could flow in both directions and the sinusoidal expected waveform is highly distorted, accuracy becomes a crucial factor for the correct values of electrical energy and power for the purposes of revenue and/or control.

Standards for electricity meters [2]-[4], currently used for international certification, provides requirements for revenue meters that lack of definitions for non-sinusoidal waveforms [5]. These standards apply to electromechanical or static meters and cover different tests and test conditions. Regarding the accuracy, IEC 62053-11 standard indicates the limits of error due to variations of the current and other influence quantities and clearly states what the "normal" test conditions should be [3].

Experimental-based studies have been conducted in order to analyse the effects of non-sinusoidal waveforms on different electricity meters [6]; however, most of these studies are focused only in harmonic contents produced by non-linear loads or injected to the load using a programmable Power Source. Although many authors have proposed procedures and methods to calibrate meters under distorted waveforms, the tests and the test conditions differs widely from one to another.

Additional efforts (i.e. standard extension, technical reports and recommendations) have been made to address the non-ideal scenarios for electricity meters under non-sinusoidal and unbalanced conditions. Some of the most important documents issued at this regard are the electric power quantities defined in [7], the recommendations for testing meters in [8] or the tests for immunity to disturbances and signalling described in [9]. Nevertheless, such standards are not mandatory for revenue electricity meters to be approved by regulatory bodies up to this day.

Another relevant issue that electricity meters manufacturers faced is the flexibility to implement different algorithms to calculate the electrical energy consumed by a customer, since there is not a unique (valid) algorithm to implement in digital metering [10], when non-sinusoidal conditions exist. This flexibility leads to revenue losses for utilities and in some cases, unfair billing for customers [11].

\section{ELECTRICITY METERS FOR REVENUE AND RELATED STANDARDS}

Electricity meters for revenue can be categorised into two main groups: Electromechanical and Static meters. While Electromechanical meters have been proving to have a longer life expectancy than statics, the inherent accuracy issues due to the mechanical moving parts do not affect the electronic (static) meters. Furthermore, in recent years semiconductor manufacturers have developed low-cost metering ICs enabling high accuracy as well as new capabilities and flexibility for the new generation of Automatic Meter Reading (AMR) systems [12].

Despite the improvements on static meters and the capability to measure different electrical parameters, for purposes of revenue, only "the amount of energy delivered to a customer over an accounting interval" [11] is taken into account. Electric energy $E$, expressed in $\mathrm{kWh}$ or $\mathrm{MWh}$, is typically obtained through the integral of the active power $P$ of the load over the specified period of time $T$ as follows: 


$$
E=\int_{0}^{T} P(t) \cdot d t=\int_{0}^{T} U(t) \cdot I(t) \cdot d t
$$

The active power $P$ is obtained by the multiplication of instantaneous values of voltage $U$ and current $I$.

Although (1) is valid for sinusoidal conditions, when harmonic contents exist, it has been demonstrated that utilities could be losing revenues when applying this formula to calculate the electric energy delivered to a customer with non-linear loads [11]. An explanation of the disadvantages of using (1) as a metric for billing will be discussed later in Section III. C.

\section{A. Electromechanical meter}

The electromechanical induction electricity meter has proved to be a reliable instrument to measure electrical energy for over a hundred years and is still working in millions of households around the world, although most of the manufacturers discontinued their production since 2010 [13].

Despite the well-accepted performance by both, electricity utilities and consumers, there are two main reasons for the replacement of electromechanical meters. One reason is the limited information they can provide; commonly, electromechanical meters only measure electrical energy in kilowatt-hour (kWh) or Megawatt-hour (MWh) units. The lack of capability to transmit this information (communication capability) is the other cause of the replacement.

\section{B. Electronic meter}

Static (electronic) meters meets higher accuracy levels than previous versions and became the replacement for the electromechanical meter since the 1980s. They use measurement algorithms to calculate relevant quantities from the digitized current and voltage signals from analog sensors. This kind of meter could be able to calculate more electrical parameters like reactive energy, peak demand, time of use, power quality, as well as implement new communication capabilities [13].

The most sophisticated meters, known as Smart Meters can also determine the energy flow direction allowing new schemes for electricity generation by the costumers and dynamic tariff rates. The two-way communication system incorporated into the Smart meters makes it possible to monitor the energy usage in a shorter interval of time, providing this information to electricity producers and consumers.

Although electronic meters are capable of implementing sophisticated mathematical models to calculate electrical parameters, the lengthy discussion about definitions for electrical power quantities of distorted waveforms and unbalance has led to significative differences in the measures among meters . Theoretical calculations [10] and experimental tests [14] have confirmed such discrepancies when non-ideal conditions exist.

\section{Standards for Electricity metering equipment}

Standards for electricity metering equipment are developed by organisations like the International Electrotechnical Commission (IEC) for Europe and the American National Standards Institute (ANSI) for North America. These

Quijano Cetina R. wishes to express his gratitude to the Mexican Energy Ministry (SENER) and the National Council for Science and Technology (CONACYT) for financing this study through the Scholarship CONACYT-SECRETARIA DE ENERGIA- SUSTENTABILIDAD ENERGETICA 2016- ref.: 291041/ 439171. organisations have defined different accuracy classes for electricity meters, as well as the tests and test conditions for each class. Manufacturers and utilities should test electricity meters, meeting the requirements of applicable standards, before the deployment of the equipment. Nevertheless, such standards have been designed for quasi-ideal working conditions: sine waveforms for voltage and current, with almost no harmonic contents. Those conditions are not representative enough for the today power quality scenario. Not even for some "small" customers, where power quality issues could be produced locally due to non-linear loads or imported from a neighbour customer and/or from the electrical grid.

The European standard EN 50470-3:2006 [15], derived from IEC-62053-21:2003 and IEC-62053/22:2003 standards, establish the limits of the Maximum Permissible Error (MPE) for electricity meters to be used in Europe with the approval of the European Measuring Instrument Directive (MID). Table I shows the MPE for different Classes of electricity meters, according to the harmonised standard EN 50470-3:2006.

\section{TABLE I. MAXIMUM PERMISSIBLE ERROR LIMITS FOR MID APPROVED ELECTRICITY METERS [15]}

\begin{tabular}{|c|c|}
\hline MID Accuracy Class & Maximum Permissible Error Limits \\
\hline \multirow{3}{*}{$\begin{array}{l}\text { Electricity Meters } \\
\text { (Class A) }\end{array}$} & $\pm 2.5 \%$ at minimum current flow \\
\hline & $\begin{array}{l} \pm 2.0 \% \text { at one fifth of maximum current } \\
\text { flow }\end{array}$ \\
\hline & $\pm 2.0 \%$ at the maximum current flow \\
\hline \multirow{3}{*}{$\begin{array}{l}\text { Electricity Meters } \\
\text { (Class B) }\end{array}$} & $\pm 1.5 \%$ at minimum current flow \\
\hline & $\begin{array}{l} \pm 1.0 \% \text { at one fifth of maximum current } \\
\text { flow }\end{array}$ \\
\hline & $\pm 1.0 \%$ at the maximum current flow \\
\hline \multirow{3}{*}{$\begin{array}{l}\text { Electricity Meters } \\
(\text { Class C) }\end{array}$} & $\pm 1.0 \%$ at both minimum current flow \\
\hline & $\begin{array}{l} \pm 0.5 \% \text { at one fifth of maximum current } \\
\text { flow }\end{array}$ \\
\hline & $\pm 0.5 \%$ at the maximum current flow \\
\hline
\end{tabular}

In Table II, the maximum permissible distortion factor for sinusoidal voltages and currents signals waveforms, used for testing electricity meters according to IEC standards, is presented. It is important to notice that for any class, the distortion factor should be less than $3 \%$, even for the higher accurate meters classification.

TABLE II. SINUSOIDAL VOLTAGES AND CURRENTS WAVEFORM TOLERANCES FOR ACCURACY TEST CONDITIONS

\begin{tabular}{|c|c|c|}
\hline Standard & Class & $\begin{array}{c}\text { Distortion factor } \\
\text { less than: }\end{array}$ \\
\hline \multirow{2}{*}{$\begin{array}{c}\text { IEC 62053-11:2003 } \\
\text { (Electromechanical) }\end{array}$} & 0.5 & $2 \%$ \\
\cline { 2 - 3 } & 1 & $2 \%$ \\
\hline \multirow{2}{*}{$\begin{array}{c}\text { IEC 62053-21:2003 } \\
\text { (Static) }\end{array}$} & 1 & $3 \%$ \\
\cline { 2 - 3 } & 2 & $2 \%$ \\
\hline \multirow{2}{*}{$\begin{array}{c}\text { EN 50470-3:2006 } \\
(\text { Static) }\end{array}$} & $\mathrm{A}$ & $3 \%$ \\
\cline { 2 - 3 } & $\mathrm{B}$ & $3 \%$ \\
\cline { 2 - 3 } & $\mathrm{C}$ & $2 \%$ \\
\hline
\end{tabular}


Due to the need to extend the requirements for electricity meters under non-ideal conditions, organizations such as the IEEE, the International Organization of Legal Metrology (OIML) and the European Committee for Electrotechnical Standardization (CENELEC) have published Standard Definitions, International Recommendations and Technical Reports. These documents complement the standards aforementioned, but their requirements are not mandatory for an electricity meter for revenue to be approved by regulatory bodies. Nevertheless, they contain useful guidelines for the new electricity meter designs, or a metrics definitions update, when a firmware upgrade is possible.

In 2010, the revision of the standard IEEE 1459-2000 was approved by the IEEE-SA Standards Board. In this document, new definitions for electrical power were developed (adopted) in response to the significant errors of instrumentation equipment designed for sinusoidal $60 / 50 \mathrm{~Hz}$ waveform [7]. One important contribution of this standard is to extend the considerations to situations such as non-sinusoidal waveforms for voltage and current, load unbalance, and asymmetry of the power supply. Nonetheless, the separation of P1 and Q1 (fundamental power frequency components) from the apparent power $S$ is perhaps, the most significative contribution [5].

In 2012, the final draft of the International Recommendation OIML R 46-1 [8] was issued. This document also extends the test requirements to sinusoidal, non-sinusoidal, balanced and unbalanced conditions [16]. Particularly, the test conditions for accuracy error due to harmonic distortion have been well defined. Tests for sub-harmonic and high-order harmonic contents have been included in this document.

More recently, the final revision of IEC 61000-4-19 document was approved by CENELEC in 2014, as an extension of the EN 50470-3:2006 standard [17]. The aim of this standard is to define immunity requirements for electrical and electronic equipment "with the application of differential mode disturbances and signalling to a.c. power ports" [9]. The test methods have been specified as differential mode disturbances and signalling in the range $2 \mathrm{kHz}$ up to $150 \mathrm{kHz}$, and most of them are described for electricity meters. In Table III, an additional percentage of deviation in the measurement, allowed under conditions described in the technical report CLC/TR 50579 [18] and adopted by IEC 61000-4-19:2014, is presented. The accuracy class is the same as seen in Table I.

TABLE III. MAXIMUM Allowed PeRCENTAGe ERROR DePENDING ON THE ACCURACY CLASS [18]

\begin{tabular}{|c|c|}
\hline MID Accuracy Class & $\begin{array}{c}\text { Maximum allowed additional percentage } \\
\text { error for electricity meters of class }\end{array}$ \\
\hline A & $\pm 6 \%$ \\
\hline B & $\pm 4 \%$ \\
\hline C & $\pm 2 \%$ \\
\hline
\end{tabular}

\section{Smart Electricity Meters deployment}

In several countries all around the world, the deployment of electricity Smart Meters is taking place in order to accelerate the transition from the traditional electrical grid to the new Smart
Grid. In fact, many of the upcoming changes due to the Smart Grid approach highly depends on the availability of data from Smart Meters, either for revenue or control. Table IV shows the expected diffusion rate of electricity Smart Meters by 2020 in countries from the European Union [19]. Similar deployments are taken place in America and Asia.

TABLE IV. EXPECTED SMART ELECTRICITY METERS DEPLOYMENT IN THE EU BY 2020 (DATA FROM [19])

\begin{tabular}{|c|c|}
\hline Country & $\begin{array}{c}\text { Expected Diffusion } \\
\text { rate by 2020 }(\%)\end{array}$ \\
\hline Austria & 95 \\
\hline Czechia & 1 \\
\hline Denmark & 100 \\
\hline Estonia & 100 \\
\hline Finland & 100 \\
\hline France & 95 \\
\hline Germany & 23 \\
\hline Greece & 80 \\
\hline Ireland & 100 \\
\hline Italy & 99 \\
\hline Latvia & 23 \\
\hline Luxembourg & 95 \\
\hline Malta & 100 \\
\hline Netherlands & 100 \\
\hline Poland & 80 \\
\hline Romania & 80 \\
\hline Slovakia & 23 \\
\hline Spain & 100 \\
\hline Sweden & 100 \\
\hline United Kingdom & 100 \\
\hline & \\
\hline & \\
\hline
\end{tabular}

The Smart Meters already deployed complies with the requirements of MID, but not necessarily with the most recent standards and recommendations. It is an interesting question to answer if such meters could satisfactory meet the tests described by the new documents or if they could be upgraded with new power definitions (via firmware update), as has been done in [5].

\section{EFFECTS OF DISTORTED WAVEFORM CONDITIONS ON THE ACCURACY OF ELECTRICITY METERS}

Many efforts have been expended to quantify the effects of distorted waveform conditions on the accuracy of electricity meters. Several laboratory-based tests with non-linear loads, programmable power supplies (with random or predefined harmonic content), as well as theoretical analysis and simulations, have been reported in the literature. There either try to quantify the error or make a comparative between different technologies of electricity meters, i.e. Electromechanical versus Static Meter.

The lack of uniformity in the conditions of which those tests have been implemented, as well as the wide difference in the laboratory equipment, load characteristics, and other similar aspects has lead to discordant and sometimes contradictory results among authors.

In this section, some of the above-mentioned tests are described and the most relevant results are summarised. The tests have been divided into two categories: Performance Test and Comparative Tests. 
An additional category refers to the studies dedicated to the analysis of the impact of non-sinusoidal conditions in the electrical energy billing calculation.

\section{A. Performance Tests Review}

One of the earlier experiments for electricity meters exposed to harmonic content was reported in [20]. For this test, a set of unbalanced signals was injected to different meters. The percentage error is in the range from $-10.09 \%$ to $+0.52 \%$, for three-phase digital meters.

In [21], eight electronic meters for electricity revenue (three single phase and five three-phase) were tested according to the standard EN 50470-3, but extending the frequency range up to 3 $\mathrm{kHz}$. For this test, an Omicron CMC 256+ generator was employed for the voltage and current signals for the meters and an NI 9239 card was used to monitor the pulsed output of the meters. Authors concluded that even when all tested meters meets the accuracy of standards requirements, all of them had a different performance in presence of harmonic active power. Even more, two of those meters exhibit significative deviations, in the range from -100 to $+300 \%$ when the harmonic frequency increases.

In [22] two single phase energy meters was exposed to nonsinusoidal tests. A Chauviun Arnux 8834 (Calibrated Power Quality Analyzer) is used as a reference, connected in parallel with the meters under test. Three tests were performed as follows. Test 1 consisted of 6 Tungsten lamps (100W) injected with harmonic components of $30 \%$ from the 3 th to the 19 th. Test 2 consisted of 15 CFL (40W) connected to a $50 \mathrm{~Hz}$ sinusoidal power source. In Test 3 , the $15 \mathrm{CFL}$ are connected in parallel with an inductive single phase motor. Authors concluded that meters can acceptably measure active power under the described conditions.

Thirteen experiments were performed in [23] to six electronic meters (four different models), using a Programmable Power source and a Reference wattmeter. The tests include the different level of harmonic content up to the 50th, phase fired control load, as well as 8 PCs with LCD monitors. For some of those tests, the error of meters is as high as $6.78 \%$, when the PC cluster was connected.

\section{B. Comparative Tests Review}

Authors in [24] run three different "Distorted load" sets and one "Linear load" set for three different electricity meters: an Analogue (electromechanical), a Digital (electronic) and a hybrid meter. The loads (connected in different configurations for each set) consisted of resistive loads controlled by dimmers, Compact Fluorescent Lamps (CFL) and capacitors. The measurements of the tested meters were compared with the values obtained with a calibrated energy system analyser. In all the tests, the most accurate meter was the electromechanical and the worst performance corresponds to the electronic, with a maximum error of $6 \%$, which is not negligible at all. These results are somehow unexpected, but more recent and betterperformed tests, have been supporting such results.

One of the most recent studies [14], where ten static meters was compared with the measures of an electromechanical meter, have reported a significative deviation in the majority of static energy meters, compared with the performance of the electromechanical. The tests include LED Lamps, CFLs, Dimmer at different angles and a line choke, connected in different configurations for each test. The highest deviation values of static meters are in the order of 560 to $582 \%$ with respect to the Electromechanical.

In contrast with [24] and [14], authors in [25] reported significative errors in analogue meters when compared to the measurements of electronic meters. The tests consisted of disturbances injected to the load such as harmonics, unbalance and frequency changes. Three static meters versus three electromechanical meters were tested in this study. The equipment used for this experiment was a reference meter, a Single phase power quality analyser, a Programmable AC power source, pulse counters and a Three-phase $75 \mathrm{Ohm}$ (per phase) resistor in Wye connection.

\section{Billing Calculation Analysis review}

The billing calculation of the electrical energy $E$ delivered to a customer is well stablished and can be obtained by the integral of active power (1) under sinusoidal conditions. On the other hand, for the non-sinusoidal conditions, different approaches can be implemented, leading to different results [10], [26].

IEEE definitions for power quantities [7] seems to be a good starting point to deal with distorted waveforms measurement and the Energy which a customer shall pay for. However, there is still a disagreement about which quantities should be taken into account to calculate the final bill for the customer, in the most fair way (i.e. including or excluding the energy dissipated due to harmonics in the electrical system).

In [11], Czarnecki suggested (and theoretically proved) that using (1) as a metric to bill customers for the delivered energy, utilities can lose revenues. This is because the integral of $P$ includes both, fundamental and harmonic active power. In the case of a customer with non-linear loads (harmonic currents generated by the customer), all the active power of even harmonics $P_{h}$ flows from the load to the source (negative sign), so they are subtracted from $P$ (i.e. $P=\Sigma P_{n}=P_{0}+P_{1}+P_{2}+$ $\left.P_{4} \ldots\right)$. In such a situation, the utility provide an extra amount of energy (through the fundamental frequency) which is not charged to the customer. In a similar way, if a customer is exposed to harmonic content from the grid (positive sign), the bill will include not only the useful active energy for the customer, but also the potentially harmful active power delivered [11], [26]. Czarnecki proposed formulas (2) and (3) as the fairest approach to calculating the electrical energy charged to customers.

$$
\begin{gathered}
E_{1}=\int_{0}^{T} P_{1}(t) \cdot d t \\
E_{h}=\int_{0}^{T}\left(P_{1}(t)-P(t)\right) \cdot d t
\end{gathered}
$$

$E_{1}$ is the active energy due only to the fundamental harmonic energy power $P_{1}$ while $E_{h}$ is the energy of the nonfundamental active power. The study is extended to three-phase 
systems and concludes that "a tariff based on the energy delivered by the positive sequence component of the voltage and current fundamental harmonic, provides more justified tariff for the energy accounts in unbalanced systems with asymmetrical and distorted voltage"[11].

$$
E_{1 p}=\int_{0}^{T} P_{1 p}(t) \cdot d t
$$

Formula (4) describes the calculation proposed by Czarnecki for three-phase systems, where $E_{1 p}$ is the energy delivered by the positive sequence, at fundamental harmonic power $P_{1 p}$.

R. Carbone et al in [26] analyzed the billing scheme in an "Italian incentive for PV generation" known as "Conto Energia". Similar to [11], on this study the disadvantages of using (1) as a metric has been reported. Authors suggested the adoption of IEEE 1459 power definitions and the sequence component theory for the most "fair" manner to account the energy produced and consumed by the prosumer (energy producer and consumer). The study includes the analysis and discussion of numerical results for a prosumer with three- $6 \mathrm{kWp}$ PV strings, connected to single-phase inverters. Four different cases were analyzed, including unbalance and non-linear loads.

In 2015, Berrisford [5] successfully implement the IEEE 1459 definitions in an "off-the-shelf" Smart Meter, with the aim to prove that such definitions can be "easily" implemented in a current smart meter design by a firmware update. The author performs the tests suggested in OIML R46 and the modified meter meet the requirements. In the conclusions, Berrisford state that "harmonics tests in OIML R46, and those under consideration by ANSI and Measurement Canada, should be revised to exclude harmonic power components from the trade measure of electrical energy, rather than including them", agreeing to [11] and [26].

\section{Upcoming challenges for Smart Energy Meters}

Some of the disturbances which are expected to increase in the electrical grid during the next few years are summarised in table V. While current distortion and harmonic emission on the Grid is rapidly increasing due to policies to promote the use of energy-efficient devices, such as LED lamps and CFLs as well as Switching Active Power Electronic technologies, the effects of other phenomena like Interharmonic and Supraharmonic content on the accuracy of electricity meters remains still unknown.

On the other hand, the upgradability of meters already deployed (or been deployed) becomes a key factor to dealing with the dynamical power conditions of the grid. A Smart Meters calibration for distorted and unbalanced conditions should be a requirement, if a firmware update is feasible. This upgrade capability will allow electricity meters adapting their metrics to upcoming standards, as the electrical Smart Grid evolves [27].

In addition to the tests for non-sinusoidal and unbalance situations, requirements for smart meter design should be reviewed (and perhaps standardized) to assure an adequate frequency response of the different digital signal processing stages.

The adequate billing of electrical energy is an interesting topic closely related to the accuracy of electricity meters. Economic incentives (or penalties) for consumers and producers are only possible with the correct measure of electricity meters, in any working condition scenary.

\section{CONCLUSIONS}

In this paper, a review of current and upcoming challenges for Smart electricity meters have been presented. The understanding of the relationship between power quality and the accuracy of electricity meters is useful to evaluate the impact of including a standardised procedure to properly calibrate meters under distorted waveform.

Further and continuous investigation is required to minimize the error of electricity meters under any possible working condition. The current permissible error in applicable accuracy related standards could be a cause of significative revenue losses for utilities.

Present standards do not provide a clear guidance about what the electrical quantities of interest for billing purposes are. While considerations of the calculations for the billing to customers differs among countries, regions or even providers, the electrical parameters required to make such calculations should be clearly

TABLE V

DISTURBANCES ON THE LOW-VOLTAGE ELECTRICAL SYSTEMS DUE TO DIFFERENT TECHNOLOGIES/DEVICES

\begin{tabular}{|c|c|c|c|c|c|c|c|}
\hline & $\begin{array}{c}\text { Current } \\
\text { Distortion }\end{array}$ & $\begin{array}{c}\text { Voltage } \\
\text { Distortion }\end{array}$ & $\begin{array}{c}\text { Harmonic } \\
\text { Emission }\end{array}$ & $\begin{array}{c}\text { Interharmonic } \\
\text { Emission }\end{array}$ & $\begin{array}{l}\text { Supraharmonic } \\
\text { Emmision }\end{array}$ & Unbalance & $\begin{array}{c}\text { Capacitance } \\
\text { Increase }\end{array}$ \\
\hline LED and CFL & $\checkmark$ & & $\checkmark$ & & $\checkmark$ & & \\
\hline Dimmer & $\sqrt{ }$ & $\checkmark$ & & & & & \\
\hline $\begin{array}{l}\text { Renewable Power Sources (Solar } \\
\text { and Wind) }\end{array}$ & & & & $\sqrt{ }$ & $\checkmark$ & $\checkmark$ & $\checkmark$ \\
\hline Active Power Electronic Devices & $\bar{\checkmark}$ & & $\sqrt{ }$ & & $\sqrt{ }$ & & \\
\hline Overhead lines to cables & & & $\sqrt{ }$ & & & & $\checkmark$ \\
\hline Power Line Communication & & & & & $\sqrt{ }$ & & \\
\hline
\end{tabular}


defined in standards required for electricity meters to be certified by the regulatory bodies.

The tests and tests conditions, which takes into account actual and emerging power quality conditions of the electrical grid should be mandatory for the new Smart Meter designs.

\section{REFERENCES}

[1] NIST, "Advanced Metering in Smart Distribution Grids," National Institute of Standards and Technology Project, 2012. [Online]. Available: https://www.nist.gov/programs-projects/advanced-meteringsmart-distribution-grids. [Accessed: 01-Feb-2017].

[2] "Electricity metering equipment (AC) - General requirements, tests and test conditions - Part 11: Metering equipment, IEC 6205211:2003." 2003.

[3] "Electricity metering equipment (a.c.) - Particular requirements - Part 11: Electromechanical meters for active energy (classes 0,5, 1 and 2), IEC 62053-11:2003.”.

[4] "ANSI C12.20-2010 American National Standard for Electricity Meters- 0.2 and 0.5 Accuracy Classes." 2010.

[5] A. J. Berrisford, "A Smarter Meter: IEEE-1459 power definitions in an off-the-shelf Smart Meter," 2015 IEEE International Instrumentation and Measurement Technology Conference (I2MTC) Proceedings. pp. 830-835, 2015.

[6] B. Jakovljević, Ž. Hederić, D. Barešić, and N. Cvetković, "FEM analysis of single-phase electromechanical meter at non-sinusoidal power supply," 2016 19th International Symposium on Electrical Apparatus and Technologies (SIELA). pp. 1-6, 2016.

[7] "IEEE Standard Definitions for the Measurement of Electric Power Quantities Under Sinusoidal, Nonsinusoidal, Balanced, or Unbalanced Conditions," IEEE Std 1459-2010 (Revision of IEEE Std 1459-2000). pp. 1-50, 2010.

[8] OIML, "OIML R 46-1/-2 Active electrical energy meters. Part 1: Metrological and technical requirements.” pp. 1-72, 2012.

[9] "Electromagnetic compatibility (EMC) Part 4-19: Testing and measurement techniques - Test for immunity to conducted, differential mode disturbances and signalling in the frequency range $2 \mathrm{kHz}$ to 150 $\mathrm{kHz}$ at a.c. power ports, IEC 61000-4-19: 2014.” 2014.

[10] D. Gallo, C. Landi, N. Pasquino, and N. Polese, "A New Methodological Approach to Quality Assurance of Energy Meters Under Non-Sinusoidal Conditions," 2006 IEEE Instrumentation and Measurement Technology Conference Proceedings. pp. 1626-1631, 2006.

[11] L. S. Czarnecki, "Comments on active power flow and energy accounts in electrical systems with nonsinusoidal waveforms and asymmetry," IEEE Transactions on Power Delivery, vol. 11, no. 3. pp. 1244-1250, 1996.

[12] N. Wan and K. Manning, "Exceeding 60-Year Life Expectancy from an Electronic Energy Meter," in Proceedings Metering Asia Pacific Conference, 20-22 February 2001, 2001.

[13] EPRI, "Accuracy of Digital Electricity Meters." Electric Power Research Institute, Palo Alto, California, USA, 2010.

[14] F. Leferink, C. Keyer, and A. Melentjev, "Static energy meter errors caused by conducted electromagnetic interference," IEEE Electromagnetic Compatibility Magazine, vol. 5, no. 4. pp. 49-55, 2016.

[15] NMRO, "Electricity Meters - Disputed Meter Accuracy Report: Analysis of Electricity Meter Determinations Issued Between 2003 2014," 2015.

[16] V. Paciello, A. Pietrosanto, and P. Sommella, "Smart Sensors for Demand Response,” IEEE Sensors Journal, vol. PP, no. 99. p. 1, 2017.

[17] J. Drapela and T. Jurka, "Immunity Issues Related to Revenue Meters.' pp. 1-36, 2015.

[18] "TNI CLC/TR 50579: 2012. Electricity metering equipment (a.c.) Severity levels, immunity requirements and test methods for conducted disturbances in the frequency range $2 \mathrm{kHz}-150 \mathrm{kHz} . " 2012$.

[19] "Smart Metering deployment in the European Union," 2014. [Online]. Available: http://ses.jrc.ec.europa.eu/smart-metering-deploymenteuropean-union. [Accessed: 15-Jun-2017].

[20] A. Domijan, E. Embriz-Santander, A. Gilani, G. Lamer, C. Stiles, and C. W. Williams, "Watthour meter accuracy under controlled unbalanced harmonic voltage and current conditions," IEEE Transactions on Power Delivery, vol. 11, no. 1. pp. 64-72, 1996.

[21] J. Novotny, J. Drapela, and D. Topolanek, "Frequency response of revenue meters in measured active energy," 2016 17th International Conference on Harmonics and Quality of Power (ICHQP). pp. 524-529, 2016.

[22] M. Youhannaei, M. E. Honarmand, S. Ouni, R. Mehri, H. Mokhtari, and J. Talebi, "Performance evaluation of energy meters in nonsinusoidal environment based on IEEE 1459 standard," 22nd International Conference and Exhibition on Electricity Distribution (CIRED 2013). pp. 1-4, 2013.

[23] P. Bilik, M. Prauzek, and T. Josefova, "Precision check of energy meters under nonsinusoidal conditions," 22nd International Conference and Exhibition on Electricity Distribution (CIRED 2013). pp. 1-4, 2013.

[24] A. Haas, J. Niitsoo, P. Taklaja, and I. Palu, "Analysis of electricity meters under distorted load conditions," 2012 Electric Power Quality and Supply Reliability. pp. 1-4, 2012.

[25] A. Ortiz, M. Lehtonen, M. Mañana, C. J. Renedo, S. Muranen, and L. I Eguíluz, "Evaluation of Energy Meters' Accuracy Based on a Power Quality Test Platform," Electr. Power Components Syst., vol. 35, no. 2, pp. 221-237, Feb. 2007.

[26] R. Carbone, R. Langella, and A. Testa, "On the billing of electrical energy flows at prosumers' busbar," Proceedings of 14th International Conference on Harmonics and Quality of Power - ICHQP 2010. pp. 17, 2010.

[27] A. F. Snyder, B. Rankin, I. B. Snyder, and T. Swain, "The realities of testing meter firmware upgradeability," 2014 Clemson University Power Systems Conference. pp. 1-5, 2014. 